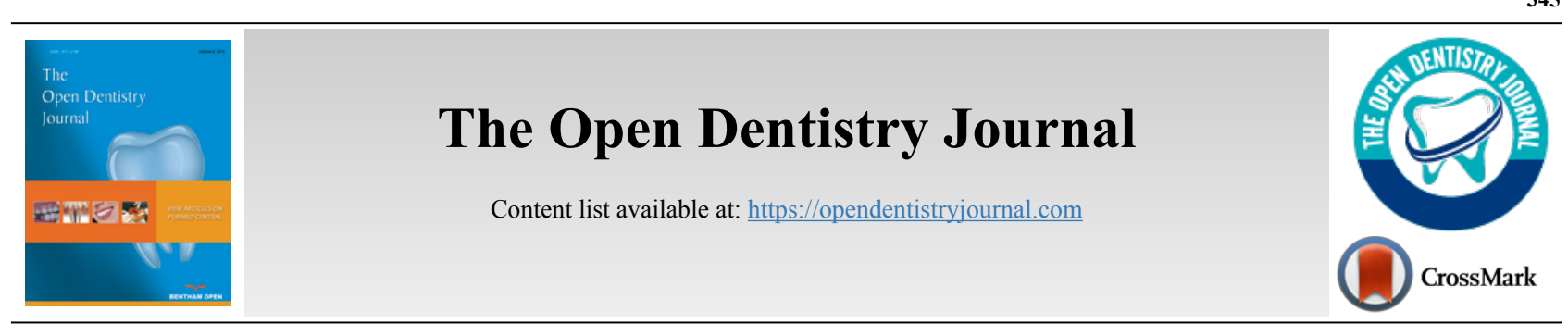

$\mathbf{E}^{\prime, 725, \$ /}$

\title{
Quarantine and Isolation are the two Integral Pillars to Dodge COVID-19 Outbreak
}

\author{
Sankha Bhattacharya, ${ }^{1, *(D)}$ and Sourabh Kosey ${ }^{2}$ \\ ${ }^{1}$ Department of Pharmaceutics, ISF College of Pharmacy, Moga, Punjab-142001, India \\ ${ }^{2}$ Department of Pharmacy Practice, ISF College of Pharmacy, Moga, Punjab-142001, India
}

Basically coronavirus (COVID-19), an evolving zoonotic infection is caused due to the infection widespread by newly identified coronavirus [1]. On $31^{\text {st }}$ December, 2019 in Chinese Wuhan province, first case of coronavirus was identified [2]. Mostly the patients who are infected with COVID-19 possess mild to moderate respiratory syndrome but the patients who are already suffering from cardiovascular disease, diabetics, chronic respiratory disease and certain immune compromised conditions viz. cancer are most suspectable for coronavirus infections [3]. There is no specific treatment available to tackle such viral infections. However, social distancing [4], sanitization (with $60 \%$ alcohol), washing hands for 20-30 seconds, evading touching of your face could avoid contamination to some extend. As per scientific reports, it was identified that COVID-19 spread primarily from salivary discharge like cough and sneezing [5]. Right now, no approved vaccines or medicaments are available in the market to tackle COVID-19, however, many clinical pieces of research are going on to find the best solution for COVID-19. As far as the coronavirus classifications are concerned, there are at list seven strains of coronavirus reported i.e., Human coronavirus 229E(HCoV-229E), Human coronavirus OC43(HCoV-OC43), SARS-CoV, Human coronavirus NL63(HCoV-NL63, New Heaven Coronavirus), Human Coronavirus HKU, Middle East Respiratory Syndrome Coronavirus (MERS-CoV) [6] previously known as novel coronavirus 2012 and HCoV-EMC, Novel coronavirus (2019-nCoV) also known as Wuhan pneumonia or Wuhan coronavirus. The coronaviruses HCoV-229E, -NL63, -OC43 and HKU1 frequently circulate in human population and cause respiratory infection in adults and children. The incubation period for human coronavirus is 2 to 5 days. Since it is a communicable disease, the transfer of this virus is due to community transfer. Hence, it is essential to break the community transfer chain [7]. On January 30, 2020

\footnotetext{
* Address correspondence to this author at the Department of Pharmaceutics, ISF College of Pharmacy, GT Road (NH-95), Ghal Kalan, Moga, Punjab 142001, India; Tel: +917878777207; E-mail: sankhabhatt@gmail.com
}

due to the savior proliferation of COVID-19 across the globe, World Health Organization (WHO) constituted Public Health Emergency of International Concerned. WHO has given its consciences that reduce human-to-human contact is the only solution to curtail COVID-19 epidemic, since we have not introduced with any medicaments so far.

As per World Health Organization (WHO) advisory [8], the community transfer chain can be wrecked or dismantled by performing two main activity i.e., Quarantine and Isolation [9]. In general, a quarantine means following strict isolation. As per Centers for Disease Control and Prevention (CDC) a Quarantine person is a person who has prehistory of visiting an infected place or an infected person [10]. The person is suspectable for spreading communicable diseases. These types of persons need to be kept in self-isolation for 7-14 days [11]. The main reason for practicing quarantine is to identify any symptomatic behavioral or physiological changes within the subject. The proper implementation of quarantine helps to spot and stop the spread of the disease. There is another term called self-quarantine, which means someone voluntarily self-isolate himself/herself out of caution. As per WHO guideline, a selfquarantine person must be given a separate room with sufficient ventilation and should be separated from the returnee. Nevertheless, a self-quarantine person should maintain at list one-meter distance from his/her family members. A self-quarantine person must be having separate bathroom and the person must be examined to check elevation of body temperature at list twice daily [12]. If he/she develops symptoms of cough, fever, breathing problem, sore throat, body pain or any flu like symptoms should immediately inform to local health authorities. During self- quarantine, the person should avoid touching his/her face, eyes, nose and wash hand for at least 20 seconds using soap and water. If the person is using disposable face mask or gloves, these Personal Protective Equipment (PPE) must be discarded after use in a close container without rethinking of using it further [13]. A selfquarantine person must be given sperate drinking glass, cups, 
eating utensil, beddings, etc. The quarantine is always under legal framework of international Health Regulations (2005) mentioned under article 30 (travelers under public health observation), article 31 (health measures related to the entry of travelers) and article 32 (treatment of travelers). However, WHO has drafted manty provisions before imposing quarantine to any territory or country i.e., the person who is under quarantine needs to be provided financial, healthcare, social, pomological support. The biggest hurdle of imposing proper quarantine is the cultural, geographical, economical factors. As per the recommendation from WHO, patient must be quarantined in hospitals only after proper identification of laboratory confirmed COVID-19 patients for 14 days. While treating quarantine patients, healthcare professionals are advised to practice proper procedure for utilizing Personal Protective Equipment (PPE) i.e., face shields, gloves, goggles and glasses, gowns, head covers, masks, respirators, and shoe covers. As per the recent statistics, COVID-19 is more prone in elderly patients, hence proper attention is need to be given to elderly patients in quarantine. Another most significant activity while in quarantine is to ensure proper respiratory hygiene. It has always been advised to cover his/her nose and mouth with bent elbow or paper tissue and mouth with bent elbow or paper tissue while sneezing. While treating quarantine patients, proper cleaning and disinfection procedure must be followed. To clean the frequently touch surfaces such as table, bed, bedroom furniture, WHO recommends daily household disinfection using dilute bleach solution (one-part bleach and 99 parts of water) the surface can not be clean with bleach can be clean with $70 \%$ ethanol. For cleaning the bathroom and toilet of quarantine patient, same procedure can be followed. For cleaning bed lines, towels, etc., WHO recommends a regular laundry soap at $60-90^{\circ} \mathrm{C}$, while washing and with proper drying of clothes. The wastage of quarantine patients must be disposed of in a sanitary landfill and localized publicly exposed area. While clearing the quarantine patient's premises, the cleaning person should take necessary precautionary steps like wearing disposable gloves while cleaning surfaces of handling line exposed with the body fluid of quarantine patient. As per Barbara Nussbaumer-Streit et al (2020) published rapid review [14], early implementation of quarantine is essential to fight COVID-19. In their investigations, the authors included 29 studies comprising of 10 modeling studies on COVID-19. The modeling studies proportionately recommends the benefits of quarantine measures.

As far as the isolation is concerned, separation of individuals who are COVID-19 positive it is referred and who are having respiratory disorder, fever $\&$ high symptoms of COVID-19 infection [15]. The individual should be kept in isolation or buffer zone/containments till proper diagnosis is made. To identify the viral RNA available within the reckoned samples i.e., upper and lower respiratory mucous, nasal fluid etc. a molecular test called real-time Reverse Transcriptionpolymerase Chain Reaction (rRT-PCR) are versatilely in use while patients are in isolation [16]. As per Central for Disease Control and Prevention (CDC) there must be either a positive rRT-PCR result for at least two definite genomic targets or single positive target with the sequencing of a second target. As per CDC, the United States has approved an rRT-PCR assay for MERS-CoV [17]. The test is thru under the buff of an emergency use authorization. The patients to be kept in isolation until two unremitting rRT-PCR test comes negative. While isolation, patients need to be treated in Intensive care beds as patients are subjected to witness pneumonia or any other respiratory complications. In savior case, certain patients may witness multiorgan failure. Hence, critical care facilities, salvage therapy, dialysis facility, Extra Corporeal Membrane Oxygenator (ECMO) [18] need to be arranged and kept for a contingency plan. While keeping in the isolation, there are certain modalities need to be followed for COVID-19 patients viz. patients can be isolated in individual isolation rooms or negative pressure rooms with 12 or more air-changes per hour, all COVID-19 positive patients should be in coherence and provide proper ventilation in the ward, minimum one meter distance need to be maintain between two head-to-head beds. All patients should wear triple layer surgical masks all the time and healthcare professionals are advised to were N-95 masks [19]. Proper bio-medical west management is needful along with proper disposal of Personal Protective Equipment's (PPEs) [20]. Cleaning the isolation ward floor with phenolic disinfectants and cleaning of surface with sodium hypochlorite solution is very essential. As per National Center for Disease Control (NCDC) following checklist must be fulfilled within isolation ward: Standard clinical management protocols, standard protocols for hand hygiene, standard IEC, collection container for used equipment, linen bags, appropriate clinical waste bags, large plastic bags, appropriate detergent, sharps containers, clean single-use towels, plain soap, alcohol-based hand rub, plastic aprons, single-use long-sleeved fluid-resistant or reusable nonfluid-resistant gowns, gowns and aprons, medical (surgical or procedure) masks, N95, FFP2 or equivalent, hair covers, latex single-use gloves for clinical care, reusable vinyl or rubber gloves for environmental cleaning, gloves, face shield (provides eye, nose and mouth protection), eye protection (visor or goggles).

As humankind is always optimistic by nature, it is expected to have a possible solution in upcoming days to vandalize COVID-19. But until we come up with a tangible solution, it is necessary to implicate available precautionary measures against COVID-19. In this direction quarantine and isolation play a pivotal role indeed!

\section{REFERENCES}

[1] Jia L, Li K, Jiang Y, Guo X, et al. Prediction and analysis of Coronavirus Disease 2019 arXiv preprint arXiv 2003. 05447. 2020 Mar 11

[2] Li Q, Guan X, Wu P, et al. Early transmission dynamics in Wuhan, China, of novel coronavirus-infected pneumonia. In: N Engl J Med. 2020; 26;382: pp. (13)1199-207.

[3] Vellingiri B, Jayaramayya K, Iyer M, et al. COVID-19: A promising cure for the global panic. Sci Total Enviro 2020; 10;725: 138277.

[4] Dalton C, Corbett S, Katelaris AJTMJoA. Pre-emptive low cost social distancing and enhanced hygiene implemented before local COVID-19 transmission could decrease the number and severity of cases. Med J Australia 2020; 212(10): 1.

[http://dx.doi.org/10.2139/ssrn.3549276]

[5] Balachandar V, Mahalaxmi I, Kaavya J, et al. COVID-19: emerging protective measures Eur Rev Med Pharmacol Sci 2020; 24(6): 3422-5.

[6] McIntosh K, Perlman S. Coronaviruses, including severe acute respiratory syndrome (SARS) and Middle East respiratory syndrome (MERS) In: Mandell, Douglas, and Bennett's Principles and Practice 
of Infectious Diseases. 2015; pp. 1928-36. e2

[7] Organization WH. Consensus document on the epidemiology of severe acute respiratory syndrome (SARS). World Health Organization 2003.

[8] Organization WH. Considerations for quarantine of individuals in the context of containment for coronavirus disease ( COVID-19): interim guidance, 29 February 2020. World Health Organization 2020

[9] Wilder-Smith A, Freedman DJJotm. Isolation, quarantine, social distancing and community containment: pivotal role for old-style public health measures in the novel coronavirus 2019.

[10] COVID, C. and R.J.M.M.M.W.R. Team, Severe outcomes among patients with coronavirus disease 2019 (COVID-19) — United States, February 12-March 16, 2020 2020; 69(23): 343-6.

[11] Wilson N, Barnard LT, Baker M. Rationale for Border Control Interventions and Options to Prevent or Delay the Arrival of Covid-19 in New Zealand. Final Commissioned Report for the New Zealand Ministry of Health 2020.

[12] Ng Y, Li Z, Chua XY, et al. Evaluation of the effectiveness of surveillance and containment measures for the first 100 patients with COVID-19 in Singapore January 2-February 29, 2020

[13] World Health Organization Laboratory biosafety guidance related to coronavirus disease 2019 (COVID-19): interim guidance. World Health Organization 2020; 2020.
[14] Mahase E. Covid-19: Quarantine works when introduced early alongside other measures, finds review. British Medical Journal Publishing Group 2020.

[15] Sohrabi C, Alsafi Z, O'Neill N, et al. World Health Organization declares global emergency: A review of the 2019 novel coronavirus (COVID-19). Int J Surg 2020.

[16] Mohammed S, Birhan G, Admassu B, et al. Review on Polymerase Chain Reaction and its Diagnostic Merit Over Conventional Techniques in Animal Disease. 2015; 7: pp. (5)262-81.

[17] Abdel-Moneim ASJAov. Middle East respiratory syndrome coronavirus (MERS-CoV): evidence and speculations 2014; 159(7): 1575-84.

[18] MacLaren G, Fisher D, Brodie DJJ. Preparing for the most critically ill patients with COVID-19: the potential role of extracorporeal membrane oxygenation. Jama 2020; 7;323(13): 1245-6. [http://dx.doi.org/10.1001/jama.2020.2342]

[19] Ng K, Poon BH, Kiat Puar TH, et al. COVID-19 and the risk to health care workers: A case report Ann Intern Med 2020; 2;172(11): 766-7.

[20] Organization WH. World Health Organization. Rational use of Personal Protective Equipment (PPE) for coronavirus disease (COVID-19): interim guidance, 19 March 2020. World Health Organization 2020.

C) 2020 Bhattacharya and Kosey.

This is an open access article distributed under the terms of the Creative Commons Attribution 4.0 International Public License (CC-BY 4.0), a copy of which is available at: (https://creativecommons.org/licenses/by/4.0/legalcode). This license permits unrestricted use, distribution, and reproduction in any medium, provided the original author and source are credited. 